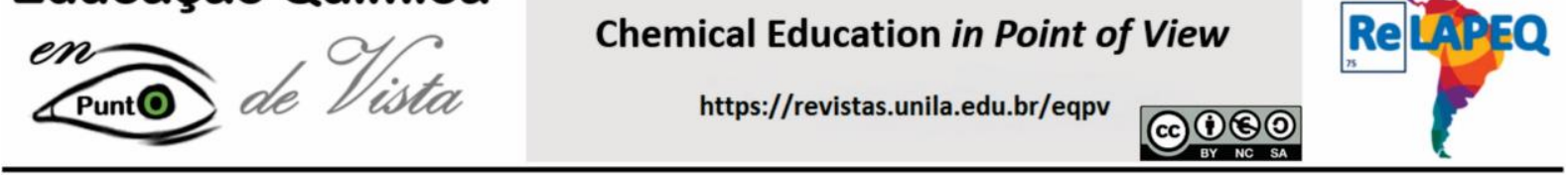

DOI: https://doi.org/10.30705/eqpv.v5i1.2538

\title{
Os conhecimentos basilares mobilizados no estágio supervisionado de Química
}

\author{
Eliane Aparecida dos Santos ${ }^{1}$, Leila Inês Follmann Freire ${ }^{2}$ \\ ${ }^{1}$ Mestra em Ensino de Ciência pela Universidade Estadual de Ponta Grossa (UEPG, Brasil) \\ ${ }^{2}$ Doutora em Ensino de Ciências pela Universidade de São Paulo \\ Professora da Universidade Estadual de Ponta Grossa (UEPG)
}

\section{The basic knowledge mobilized in the Supervised Internship Chemistry}

Informações do Artigo

Recebido: 31/08/2020

Aceito: $13 / 01 / 2021$

Palavras-chave:

Base de Conhecimento; Estágio

Curricular; Formação Inicial de

Professores.

\section{Key words:}

Knowledge Base; Curricular stage;

Initial teacher training.

E-mail: elianedosantos0@gmail.com

\begin{abstract}
A B S T R A C T
This study is located in the field of teacher training and aims to identify the basic knowledge mobilized by undergraduate Chemistry students in the different planning and action instruments produced at the time in the subject of Supervised Curricular Internship. The categories used in the analysis were defined a priori from the model proposed by Abell (2007), namely: Content Knowledge, Pedagogical Knowledge, Pedagogical Content Knowledge and Context Knowledge. As main results we have the predominance of Pedagogical Content Knowledge, based on instructional strategies for teaching. Thus, we emphasize the importance of the variety of activities developed in the Supervised Curricular Internship, which permeate different knowledge of teaching.
\end{abstract}

\section{INTRODUÇÃO}

A formação de professores tem sido o foco de diversos estudos apoiadas na premissa de que existe uma base de conhecimento própria para o ensino, instigando vários pesquisadores a investigar e sistematizar esses conhecimentos ${ }^{1}$.

Sobre esses conhecimentos, Shulman $(1986 ; 1987)$ estabeleceu a ideia do ensino que enfatiza a compreensão, transformação e a reflexão referente aos conhecimentos aprendidos ao longo de processos formativos e do exercício profissional. Para o ensino esse conhecimento consiste de um corpo de compreensão, habilidades e capacidades, traços e sensibilidades.

Para Shulman, o termo conhecimento concerne àquilo que todo professor deve/deveria entender sobre a docência para auxiliar no processo de ensino-aprendizagem

\footnotetext{
${ }^{1}$ Usaremos como sinônimos no texto as expressões Conhecimentos de Professores, Base de Conhecimentos, Conhecimentos Docentes, Base de Conhecimento de Ensino.
} 
DOI: https://doi.org/10.30705/eqpv.v5i1.2538

mais eficiente, e aponta que "professores deveriam saber fazer, compreender ou professar para converter o ensino em algo mais que uma forma de trabalho individual e para que seja considerada entre as profissões prestigiadas" (SHULMAN, 1987, p.5).

Ao investigar os conhecimentos dos professores, Shulman (1986), propõe três categorias de Conhecimento dos professores: Conhecimento do Conteúdo Específico, Conhecimento Pedagógico do Conteúdo e Conhecimento do Currículo. Em 1987, Shulman redefiniu essas categorias em uma lista mais abrangente, propondo que a Base de Conhecimentos para o Ensino engloba sete Conhecimentos para o professor desenvolver seu trabalho em sala de aula, definindo-as em:

- Conhecimento do Conteúdo;

- Conhecimento Pedagógico Geral, com especial referência aos princípios e estratégias mais abrangentes de gerenciamento e organização de sala de aula, que transcendem o âmbito da disciplina;

- Conhecimento do Currículo, particularmente dos materiais e programas que servem como "ferramentas do ofício" do docente;

- Conhecimento Pedagógico do Conteúdo, esse amálgama especial de conteúdo e pedagogia que é o terreno exclusivo dos professores, seu meio especial de compreensão profissional;

- Conhecimento dos alunos e suas características;

- Conhecimento de contextos educativos, que abarca desde o funcionamento do grupo ou da sala de aula, passando pela gestão e financiamento dos sistemas educacionais, até as características das comunidades e suas culturas;

- Conhecimento dos objetivos, das finalidades e dos valores educativos, e de seus fundamentos filosóficos e históricos;

A partir dos estudos de Shulman, existem diferentes propostas sobre os conhecimentos necessários para a profissão docente que se assemelham em alguns pontos, mas divergem em outros (GEDDIS et al., 1993; GROSSMAN 1990; CARLSEN, 1999; MAGNUSSON; KRAJICK; BORKO, 1999; VAN DRIEL; VERLOOP; DE VOS 1998; ROLLNICK et al., 2008; PARK; OLIVER, 2008, ABELL, 2007, dentre outros).

Como um amálgama de todos estes conhecimentos, a característica comum em vários modelos é o Conhecimento Pedagógico do Conteúdo (PCK, do inglês Pedagogical Content Knowledge) considerado um tipo específico de conhecimento profissional central dos professores, é o conhecimento que distingue, por exemplo, o professor de química de outros profissionais de química.

Grossman (1990) propôs um modelo (Figura 1) reorganizando as categorias da base de conhecimento de Shulman (1987), delimitando-as em: conhecimento do tema (que inclui o conhecimento das estruturas sintáticas, estruturas substantivas e do conteúdo); conhecimento pedagógico geral (que inclui o conhecimento dos alunos e sua aprendizagem, 
DOI: https://doi.org/10.30705/eqpv.v5i1.2538

a gestão da sala de aula, currículo, instrução e outros); conhecimento do contexto (composto pelo conhecimento do estudante em relação à comunidade, distrito e a escola) e; conhecimento pedagógico do conteúdo (que inclui a concepção dos propósitos para ensinar um conteúdo específico que constitui o conhecimento da compreensão dos estudantes, currículo e das estratégias instrucionais), sendo que, este último ocupa uma posição central na base de conhecimento de professores.
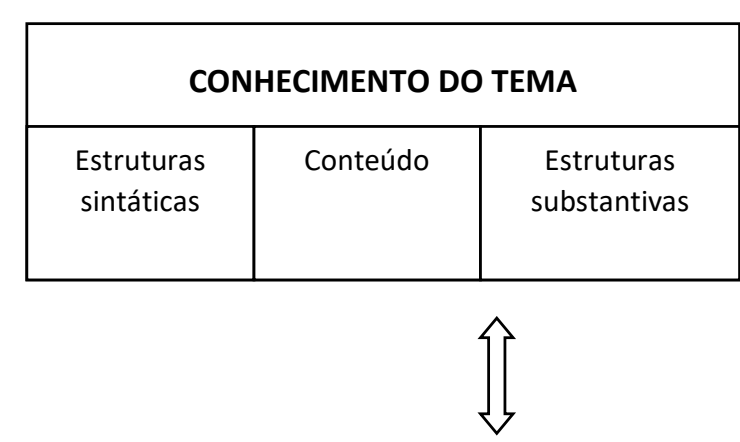

\section{CONHECIMENTO PEDAGÓGICO GERAL}

\begin{tabular}{|c|c|c|c|}
\hline $\begin{array}{c}\text { Alunos e } \\
\text { aprendizagem }\end{array}$ & $\begin{array}{c}\text { Gestão da } \\
\text { sala de } \\
\text { aula }\end{array}$ & $\begin{array}{c}\text { Currículo e } \\
\text { instrução }\end{array}$ & Outros \\
\hline
\end{tabular}

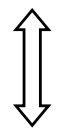

\begin{tabular}{|c|c|c|}
\hline \multicolumn{3}{|c|}{ CONHECIMENTO PEDAGÓGICO DO CONTEÚDO } \\
\hline \multicolumn{2}{|c|}{ Concepção dos propósitos para o ensino do assunto } \\
\hline $\begin{array}{c}\text { Conhecimento da } \\
\text { compreensão dos } \\
\text { estudantes }\end{array}$ & $\begin{array}{c}\text { Conhecimento } \\
\text { do currículo }\end{array}$ & $\begin{array}{c}\text { Conhecimento das } \\
\text { estratégias } \\
\text { instrucionais }\end{array}$ \\
\hline
\end{tabular}<smiles>[CH]=C</smiles>

\begin{tabular}{|l|c|c|}
\hline \multicolumn{3}{|c|}{ CONHECIMENTO DO CONTEXTO } \\
\hline \multicolumn{3}{|c|}{ Estudantes } \\
\hline Comunidade & Distrito & Escola \\
& & \\
\hline
\end{tabular}

Figura 1 - Modelo da relação entre os Domínios do Conhecimento do Professor.

Fonte: Grossman (1990), tradução de Fernandez (2015).

Um modelo de PCK (Figura 2), que segue basicamente a mesma proposta de Grossman (1990) para este constructo, foi proposto por Magnusson, Krajcik e Borko (1999), acrescentando o Conhecimento da Avaliação nas Ciências como um dos componentes do PCK e redefinindo o que Grossman (1990) designou como categoria "concepções dos propósitos para o ensino de um conteúdo" para "Orientações para o Ensino de Ciências", sendo essas 
DOI: https://doi.org/10.30705/eqpv.v5i1.2538

definidas como "conhecimentos e crenças dos professores sobre os propósitos e objetivos para o ensino de ciências em uma determinada série" (p. 97, tradução nossa).

As Orientações para o ensino de ciências são explicitadas por Magnusson, Krajcik e Borko (1999) em nove diferentes orientações: Processo; Rigor Acadêmico; Didática; Mudança Conceitual; Atividade Dirigida; Descoberta; Baseada em Projetos; Ciência; Investigação; e Investigação Orientada. As orientações foram descritas com relação aos objetivos do ensino de ciências que um professor com aquela orientação possui e as características típicas da instrução a serem conduzidas pelo professor com uma dada orientação.

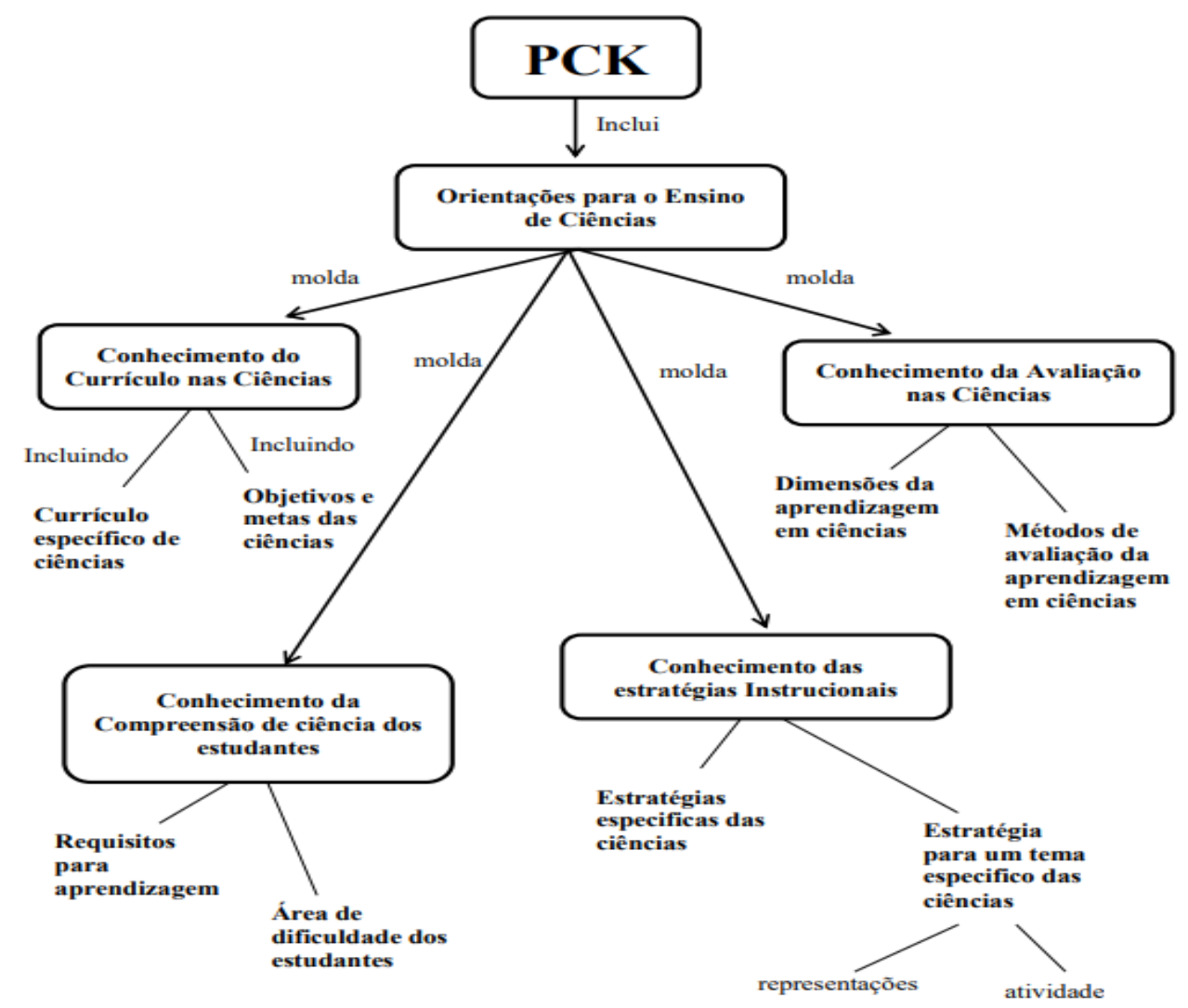

Figura 2 - Componentes do Conhecimento Pedagógico do Conteúdo para o Ensino de Ciências. Fonte: Magnusson, Krajcik e Borko (1999, p. 99), tradução de Fernandez (2015).

Abell (2007) apresenta um modelo da Base de Conhecimentos, fundamentado nos modelos de Grossman (1990) e de Magnusson, Krajcik e Borko (1999), destacando que o Conhecimento Pedagógico do Conteúdo (PCK) influencia e é influenciado pela transformação de outros três conhecimentos base: Conhecimento do Conteúdo (SMK), Conhecimento Pedagógico (PK) e Conhecimento do Contexto (CK), formando os quatro domínios principais do conhecimento profissional dos professores (Figura 3). 


\section{Educação Química}

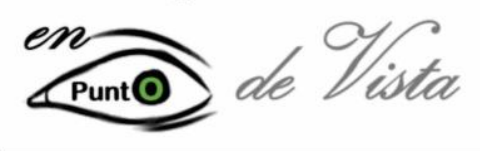

\section{Chemical Education in Point of View}

https://revistas.unila.edu.br/eqpv

\section{(1)(0)}

DOI: https://doi.org/10.30705/eqpv.v5i1.2538

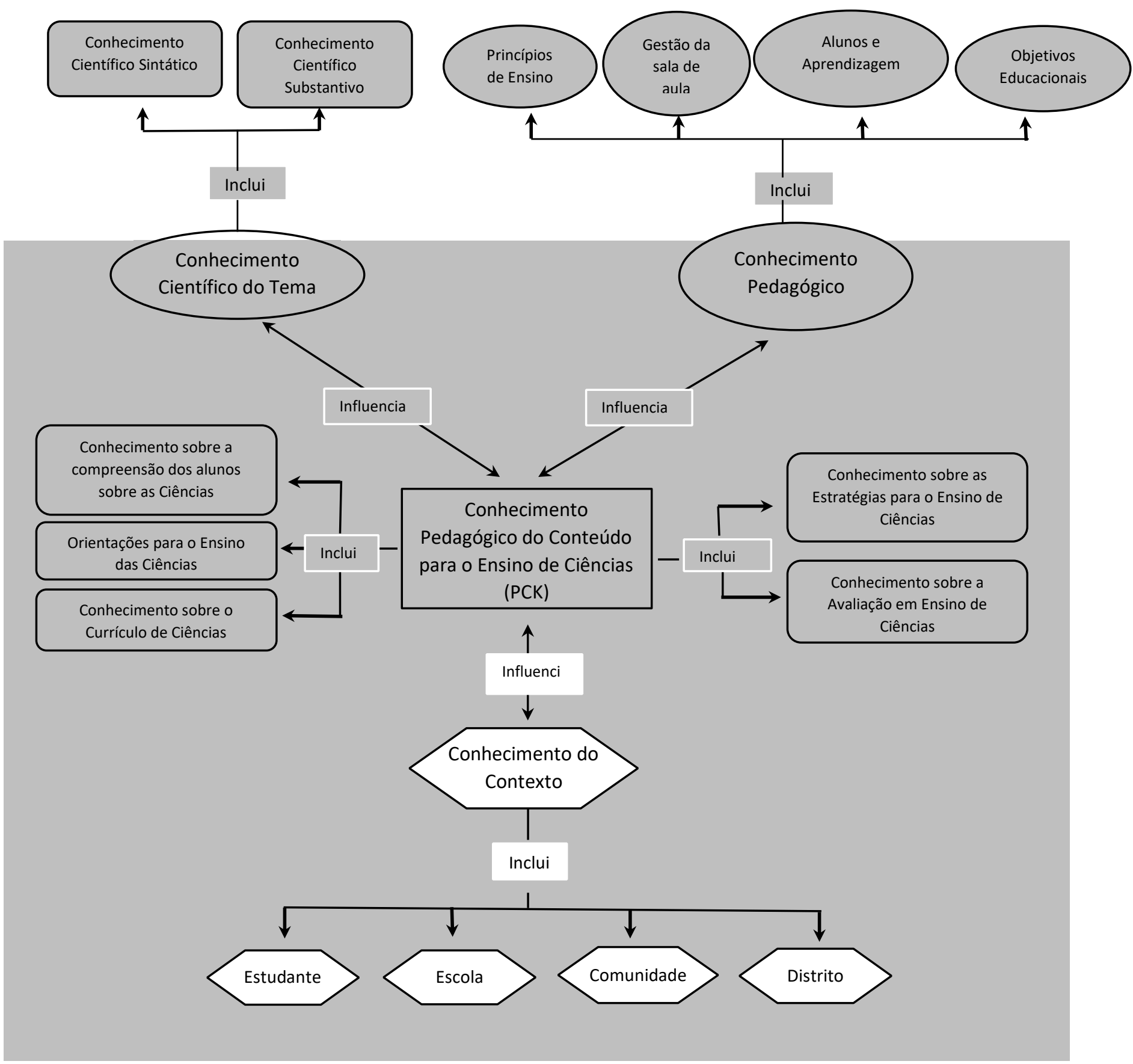

Figura 3 - Modelo de Conhecimento de Professores de Ciência.

Fonte: Modificado de Grossman (1990) e Magnusson, Krajcik e Borko, (1999). Retirado de Abell (2007), tradução nossa. 


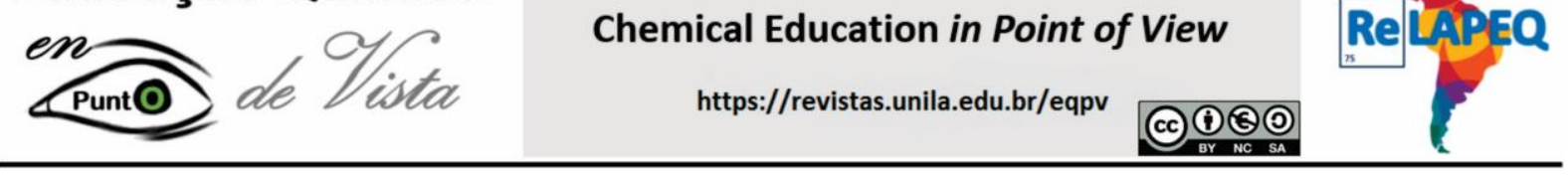

DOI: https://doi.org/10.30705/eqpv.v5i1.2538

Um campo que favorece a mobilização desses conhecimentos é o conjunto de ações da disciplina de Estágio Supervisionado², eixo curricular central nos cursos de formação de professores. Para Almeida e Pimenta (2014) essa etapa que constitui a formação inicial de professores pode:

[...] favorecer a mediação entre professores e alunos em formação no contexto real do exercício profissional através de estudos, análise, problematização, reflexão e proposição de soluções para o ensinar e o aprender, o compreender a reflexão sobre as práticas pedagógicas, trabalho docente e as práticas institucionais, situados em contextos sociais, históricos e culturais (ALMEIDA; PIMENTA, 2014, p. 30).

Nessa perspectiva, Silva e Schnetzler (2008) sinalizam no sentido de o Estágio Supervisionado ser mediador para a articulação entre teoria e prática.

O Estágio Supervisionado se constitui em espaço privilegiado de interface da formação teórica com a vivência profissional. Tal interface teoria-prática compõe-se de uma interação constante entre o saber e o fazer, entre conhecimentos acadêmicos disciplinares e o enfrentamento de problemas decorrentes da vivência de situações próprias do cotidiano escolar (SILVA; SCHNETZLER, 2008, p. 48).

O estágio como componente integrador no currículo das licenciaturas, aproximação da realidade e atividade teórica, deve ser visto como uma atividade que possa ser reflexiva e que não separe teoria e prática, uma vez que, possibilita aos professores em formação inicial a articulação entre os conteúdos químicos, por exemplo, e os pedagógicos.

Dessa forma, o objetivo da investigação que realizamos é identificar os conhecimentos basilares mobilizados nos diferentes instrumentos de planejamento e ação do Estágio Curricular Supervisionado da Licenciatura em Química. As atividades desenvolvidas nas intervenções do estágio curricular em foco neste trabalho resultaram na produção de portfólios, usados como ferramenta avaliativa, que visa incentivar os professores em formação inicial a refletir sobre as experiências vivenciadas no ambiente escolar em diferentes atividades formativas, como o reconhecimento escolar, observação de aulas e regências de classe.

\section{APORTES METODOLÓGICOS}

Os dados foram coletados a partir dos materiais avaliativos contidos no Portfólio produzidos a partir das atividades realizadas em escolas públicas da rede estadual durante as disciplinas de Estágio Curricular Supervisionado (ECS) I e II no período de 2017 e 2018, por

\footnotetext{
${ }^{2} \mathrm{O}$ termo utilizado na literatura para o estágio de cursos de graduação é Estágio Supervisionado. No presente trabalho, por vezes aparecem menções à Estágio Curricular Supervisionado, uma vez que as disciplinas que foram analisadas são assim nomeadas e assumimos a abreviatura ECS para essas disciplinas do curso em que esta pesquisa foi realizada.
}

Rede Latino-Americana de Pesquisa em Educação Química - ReLAPEQ 

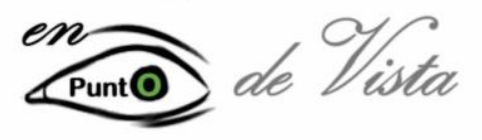

Chemical Education in Point of View

https://revistas.unila.edu.br/eqpv

DOI: https://doi.org/10.30705/eqpv.v5i1.2538

cinco licenciandos do curso de Licenciatura em Química de uma universidade pública, situada no estado do Paraná, no Brasil.

Um portfólio é um documento personalizado do percurso de aprendizagem num determinado espaço e tempo. Alarcão (2011) define como "um conjunto coerente de documentação refletidamente selecionada, sistematicamente organizada e contextualizada no tempo, reveladora do percurso profissional" (p. 60).

A produção de portfólio nas disciplinas de Estágio Curricular Supervisionado é usada como ferramenta avaliativa, onde os licenciandos apresentam as diferentes atividades formativas que desenvolveram no decorrer da disciplina, como o reconhecimento do ambiente e da comunidade escolar, observação, participação e intervenções em aulas de ciências e/ou química, coleta de dados sobre o ensino de química e a elaboração do préprojeto de ensino de química no ECS I para desenvolvimento no ECS II, resultante da pesquisa sobre sua própria prática durante as regências de classe que, ao final do segundo ano de estágio gera um artigo científico.

Detalharemos o que consta em cada material produzido na disciplina ECS I e II, que compõe o corpus desta pesquisa:

1- CoRe: é um documento elaborado para cada conteúdo específico selecionado pelos licenciandos para decidir quais as ideias centrais relacionadas ao tema ministrado e, na sequência, propor respostas às questões para cada uma das ideias centrais, a saber: a) o que você pretende que os estudantes aprendam sobre esta ideia?; b) por que é importante para os estudantes aprender esta ideia?; c) o que mais você sabe sobre esta ideia?; d) quais são as dificuldades e limitações ligadas ao ensino desta ideia?; e) que conhecimento sobre o pensamento dos estudantes tem influência no seu ensino sobre esta ideia?; f) que outros fatores influem no ensino dessa ideia?; g) que procedimentos/ estratégias você emprega para que os alunos se comprometam com essa ideia? e; h) que maneiras específicas você utiliza para avaliar a compreensão ou a confusão dos alunos sobre esta ideia?

2- Plano de aula: documento elaborado pelos licenciandos para cada uma das intervenções realizadas (regência), apontando o tema da aula, seu objetivo, o que exatamente é ensinado, a metodologia usada e a avaliação a utilizada para analisar a aprendizagem do que foi ensinado.

\section{Diários}

3.1- Diário de reconhecimento escolar: os licenciandos descrevem todas as atividades realizadas para o reconhecimento do ambiente escolar relativas ao nome e endereço da escola; núcleo de ensino que está subordinada, localização geográfica detalhando as caraterísticas culturas, sócias e lazer; funções do diretor e coordenador pedagógico, número 


\section{Educação Química}
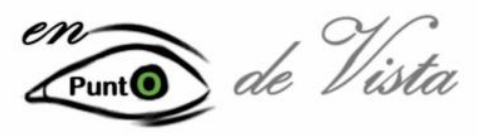

Chemical Education in Point of View

https://revistas.unila.edu.br/eqpv

DOI: https://doi.org/10.30705/eqpv.v5i1.2538

de alunos e professores, cursos que mantêm; formação dos professores responsáveis pelas disciplinas de ciências e/ou química no ensino fundamental e/ou médio; a proposta pedagógica; e observação do público escolar (perfil sócio econômico, faixa etária, conflitos, interação comunidade escola).

3.2- Diário de observação: registros para cada aula observada contendo os aspectos da gestão de classe; os recursos utilizados pelos professores como livro, experimento, jogo, etc.; a postura do professor frente à turma; a linguagem usada pelo professor; as relações interpessoais (relação aluno-professor, aluno-aluno); o planejamento do professor; o conteúdo ministrado pelo professor e avaliação.

3.3- Diários de regência: são descritas as atividades realizadas a cada aula ministrada, tais como organização e gestão da sala de aula, estratégias utilizadas para ensinar determinado conteúdo, como experimento, jogos didáticos, exercícios, etc., assim como o método de avaliação utilizado em suas aulas para avaliar a aprendizagem dos alunos.

4- Síntese reflexiva sobre o reconhecimento da escola: refletem as ações que desenvolveram no contexto da escola, as dificuldades encontradas, erros, acertos e frustrações que ocorreram durante as execuções das atividades de reconhecimento escolar.

5- Síntese reflexiva sobre as observações, participações e regências: os estagiários devem fazer uma análise sobre a sua aprendizagem no processo de todas as atividades desenvolvidas na escola.

6- Modelo de Raciocínio Pedagógico e Ação (MRPA): os licenciandos produzem um documento, com os itens do MRPA resultantes do conjunto de suas intervenções, que busca representar o processo que ocorre durante a atuação docente.

7- Materiais utilizados em sala com os alunos e roteiros de experimentos: materiais utilizados nas aulas de química como, por exemplo, texto fornecido aos alunos/passado no quadro, exercícios, avaliações (incluindo atividade avaliativa dos alunos realizada após a atividade experimental), tabelas, imagens, gráficos, vídeos, entre outros materiais.

8- Projeto de pesquisa em ensino de química e Artigo Final: O Projeto de Pesquisa em ensino de química é produzido na disciplina de ECSI, de acordo com a realidade do ambiente escolar e deve investigar e problematizar as questões de ensino-aprendizagem relacionadas a algum conteúdo de química. A partir do projeto de pesquisa proposto no ECS I e desenvolvido no ECS II, os licenciandos devem produzir um artigo científico que é defendido ao final da disciplina de ECS II perante uma banca de professores do curso de Licenciatura em Química que avaliam a qualidade do trabalho. 


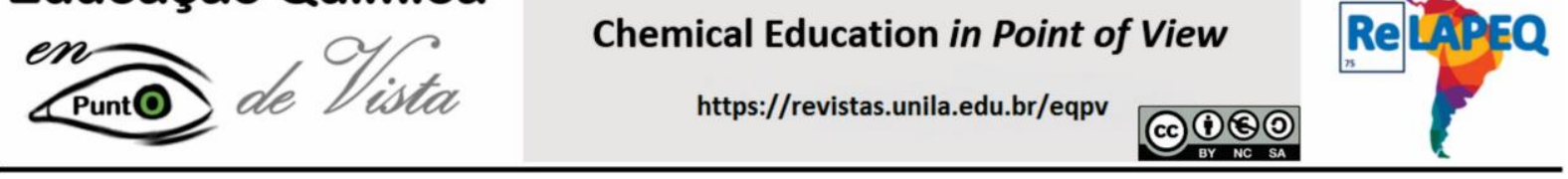

DOI: https://doi.org/10.30705/eqpv.v5i1.2538

Apresentamos no Quadro 1 o corpus composto pelos documentos dos portfólios listados no Quadro 1, o qual apresenta a definição da nomenclatura usada para nomear os documentos, identificados por um sistema alfanumérico.

Quadro 1 - Codificação dos documentos de análise.

\begin{tabular}{|l|c|}
\hline \multicolumn{1}{|c|}{ Fonte } & Código \\
\hline Representação do Conteúdo (CoRe) & D1 \\
\hline Plano de aula & D2 \\
\hline Diários (observação e regência) & D3 \\
\hline Síntese reflexiva sobre o reconhecimento da escola & D4 \\
\hline Síntese reflexiva sobre as observações, participações e regências & D5 \\
\hline Autoavaliação sobre a aprendizagem das atividades desenvolvidas & D6 \\
\hline Modelo de Raciocínio Pedagógico e Ação & D7 \\
\hline Materiais utilizados em sala com os alunos e roteiros de experimentos & D8 \\
\hline Diário de reconhecimento da escola & D9 \\
\hline Projeto de pesquisa em ensino de química e Artigo Final & D10 \\
\hline
\end{tabular}

Fonte: Autoras (2019)

Para análise dos dados seguimos as etapas da Análise Textual Discursiva que pode ser compreendida como um processo auto-organizado de construção de compreensão em que novos entendimentos emergem de uma sequência recursiva de três componentes: desconstrução dos textos do corpus, a unitarização; estabelecimento de relações entre os elementos unitários, a categorização; o captar do novo emergente em que a nova compreensão é comunicada e validada (MORAES; GALIAZZI, 2011) as quais associadas ao uso do software ATLAS.ti 8.0, consistiram em: leitura dos textos, preparação dos materiais, identificação e codificação dos documentos, criação das unidades hermenêuticas (espécie de área de trabalho dentro do software que contém todos os dados de pesquisa e categorias de análise), seleção de segmentos do texto, etc.

O processo de categorização foi realizado com categorias e subcategorias definidas a priori, com aporte nas categorias do Modelo de Conhecimento de Professores de Ciências (ABELL, 2007) complementadas pela subcategoria Conhecimento do Conteúdo (GROSSMAN, 1990). No software ATLAS.ti 8.0 foram inseridos os documentos de análise em pastas separadas (chamadas de unidades hermenêuticas) e nomeadas de acordo com a natureza de 

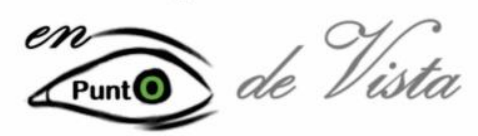

Chemical Education in Point of View

https://revistas.unila.edu.br/eqpv

DOI: https://doi.org/10.30705/eqpv.v5i1.2538

cada análise; em cada unidade hermenêutica foram criadas as categorias de análise; os documentos foram analisados (unitarizados e categorizados) e ao fim foram gerados relatórios com os números de trechos alocados em cada categoria, proveniente de cada instrumento e todas as unidades de análise (unitarizadas) incluídas em cada categoria.

\section{DISCUSSÃO}

No Quadro 2 está explicitada a quantidade de trechos de texto (unidades de análise) provenientes dos materiais produzidos pelos licenciandos durante a disciplina de Estágio Curricular Supervisionado I e II no período de 2017 e 2018, alocados em cada uma das categorias com apoio do software ATLAS.ti 8.0.

Quadro 2 - Relatório do ATLAS.ti para os Conhecimentos de Professores.

\begin{tabular}{|c|c|c|c|c|c|c|c|c|c|c|c|c|}
\hline Documentos & Ano & D1 & D2 & D3 & D4 & D5 & D6 & D7 & D8 & D9 & D10 & $\begin{array}{l}\text { Total por } \\
\text { categorias }\end{array}$ \\
\hline \multirow{2}{*}{$\begin{array}{c}\text { Conhecimento } \\
\text { Científico } \\
\text { Sintático }\end{array}$} & 2017 & 0 & 1 & 0 & 0 & 0 & 0 & 1 & 0 & 0 & 0 & \multirow{6}{*}{$\begin{array}{l}\text { SMK } \\
187\end{array}$} \\
\hline & 2018 & 0 & 0 & 0 & & 0 & 0 & 0 & 0 & 0 & 0 & \\
\hline \multirow{2}{*}{$\begin{array}{l}\text { Conhecimento } \\
\text { Cientifico } \\
\text { Substantivo }\end{array}$} & 2017 & 2 & 3 & 1 & 0 & 1 & 0 & 2 & 0 & 0 & 0 & \\
\hline & 2018 & 0 & 0 & 0 & 0 & 0 & 0 & 0 & 0 & 0 & 0 & \\
\hline \multirow{2}{*}{$\begin{array}{l}\text { Conhecimento do } \\
\text { Conteúdo }\end{array}$} & 2017 & 28 & 38 & 5 & 0 & 0 & 0 & 2 & 3 & 0 & 4 & \\
\hline & 2018 & 10 & 44 & 19 & 0 & 0 & 0 & 10 & 7 & 2 & 4 & \\
\hline \multirow{2}{*}{$\begin{array}{l}\text { Princípios de } \\
\text { Ensino }\end{array}$} & 2017 & 1 & 4 & 3 & 0 & 1 & 2 & 1 & 0 & 0 & 1 & \multirow{8}{*}{$\begin{array}{l}\text { PK } \\
306\end{array}$} \\
\hline & 2018 & 0 & 1 & 3 & 0 & 0 & 0 & 0 & 0 & 0 & 2 & \\
\hline \multirow{2}{*}{$\begin{array}{c}\text { Gestão de Sala de } \\
\text { Aula }\end{array}$} & 2017 & 0 & 43 & 48 & 0 & 11 & 10 & 7 & 0 & 2 & 0 & \\
\hline & 2018 & 1 & 76 & 31 & 1 & 0 & 5 & 6 & 0 & 3 & 4 & \\
\hline \multirow{2}{*}{$\begin{array}{c}\text { Alunos e } \\
\text { Aprendizagem }\end{array}$} & 2017 & 0 & 4 & 3 & 0 & 0 & 0 & 1 & 0 & 0 & 0 & \\
\hline & 2018 & 1 & 0 & 0 & 0 & 0 & 0 & 0 & 0 & 0 & 0 & \\
\hline \multirow{2}{*}{$\begin{array}{c}\text { Objetivos } \\
\text { Educacionais }\end{array}$} & 2017 & 2 & 1 & 2 & 0 & 1 & 3 & 1 & 0 & 1 & 7 & \\
\hline & 2018 & 1 & 8 & 4 & 0 & 0 & 0 & 0 & 0 & 0 & 1 & \\
\hline
\end{tabular}




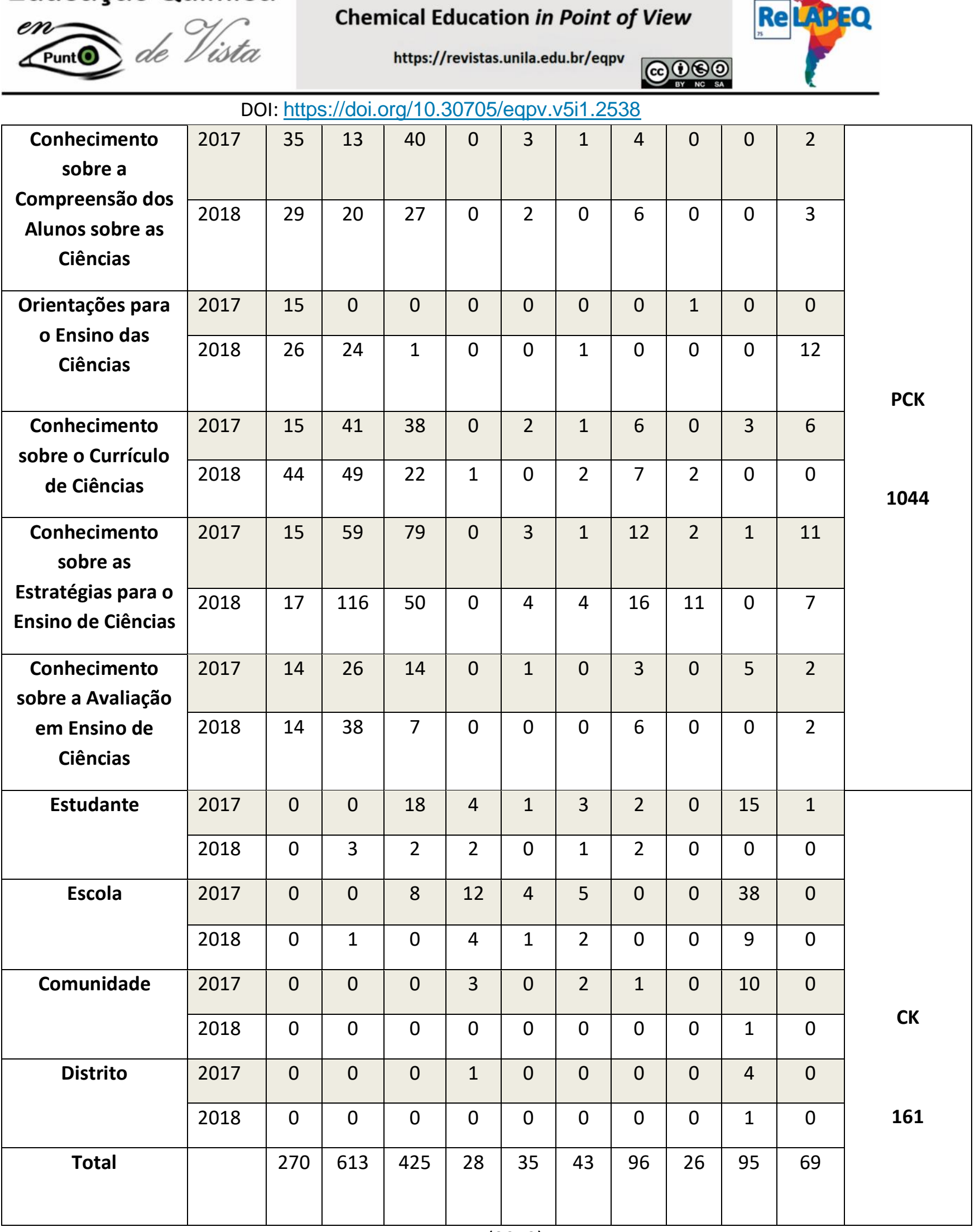

Fonte: as autoras (2019).

Foram selecionados em todas as categorias 1698 trechos, isso em razão de alguns trechos terem sido alocados em mais de uma categoria da Base de Conhecimentos para o 


\section{Educação Química}
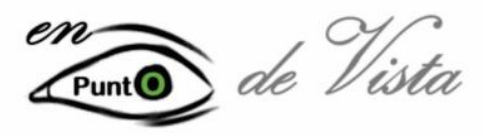

Chemical Education in Point of View

https://revistas.unila.edu.br/eqpv

DOI: https://doi.org/10.30705/eqpv.v5i1.2538

Ensino. Nas análises dos dados observa-se que a categoria com maior quantidade de menções é o Conhecimento Pedagógico do Conteúdo (1044 trechos), seguido da categoria de Conhecimento Pedagógico Geral (306 trechos), decorrendo, Conhecimento do Tema (187 trechos) e Conhecimento do Contexto (161 trechos).

A seguir apresentamos os resultados seguindo a ordem decrescente de trechos alocados em cada categoria da Base de Conhecimentos para discussão dos aspectos mais qualitativos e analíticos.

\section{Conhecimento Pedagógico do Conteúdo}

Nesta categoria foram considerados trechos que explicitam abordagens do conhecimento dos licenciandos relativo às metas e objetivos da disciplina de química para seus alunos, materiais relevantes para o ensino, compreensão das diferentes abordagens e sobre os pré-requisitos para a aprendizagem dos alunos, o conhecimento sobre o que avaliar ao desenvolver sua aula, bem como os métodos de avaliação e as estratégias específicas e que são úteis para ajudar os alunos a compreender os conceitos da disciplina de química.

Os documentos que mais contém menções na subcategoria Conhecimento sobre as Estratégias para o Ensino de Ciências, temos as atividades de observações, participações e planejamento das intervenções em aulas de ciências e/ou química que apareceram diversas vezes e contabilizaram maior número de categorias. Portanto, a partir das análises dos documentos D2 (175 trechos) e D3 (129 trechos) é possível identificar que os discursos da subcategoria de Conhecimento sobre as Estratégias para o Ensino de Ciências englobam aspectos das ações desenvolvidas pelos licenciandos para organizar as atividades de ensino e atingir os objetivos em relação ao conteúdo específico, como por exemplo, os métodos de ensino, representações e atividades:

(...) Fazer o experimento do teste de chama de forma expositiva, com a participação dos alunos, utilizando 5 sais ( $\left.\mathrm{NaCl}, \mathrm{LiCl}, \mathrm{KCl}, \mathrm{CaCl}_{3}, \mathrm{BaCl}_{2}\right)$, afim de relacionar com o conteúdo de excitação eletrônica visto em sala de aula. Logo após o experimento, apresentar exemplos do cotidiano.(..) realizar o experimento da fluorescência e a queima do magnésio de forma expositiva (Portfólio 2017 - D2, grifo nosso)

(...) A abordagem desta aula foi sobre hidrocarbonetos, onde a prof. preparou a aula nos slides, com conceitos e exemplos, assim ela pode explicar com figuras para ilustrar os conceitos que ela trouxe, como também exemplos do dia a dia e também trouxe um vídeo sobre o petróleo, onde o vídeo mostrava todas as etapas do petróleo, com isso a Prof.a foi pausando o vídeo e explicando (Portfólio 2017 - D3, grifo nosso).

$\mathrm{Na}$ análise dos planos de aulas (D2) é possível identificar no discurso mencionado acima que o método de ensino utilizado pelo licenciando em seus planejamentos para 
DOI: https://doi.org/10.30705/eqpv.v5i1.2538

intervenções em aulas de química é a utilização de experimentos para realizar o objetivo proposto da aula, sendo possível identificar o conhecimento de atividades e materiais utilizados em seu ensino para melhor compreensão e aprendizagem dos seus alunos sobre o conteúdo abordado na disciplina de química. No discurso dos diários (D3), a observação de aulas realizada na atividade do estágio, observa-se que o professor em formação inicial nota quais são os recursos e as ilustrações para explicar o conteúdo de hidrocarbonetos que são utilizadas pelo professor supervisor da escola para auxiliar a aprendizagem dos alunos.

\section{Conhecimento Pedagógico Geral}

Nesta categoria englobam aspectos gerais, que vão além do conhecimento específico, inclui o conhecimento do professor sobre as abordagens dadas por ele, seus alunos, os princípios e estratégias abrangentes de gestão e organização da sala de aula, relação professor aluno e interação entre seus alunos.

A subcategoria que integra a maior incidência de trechos no Conhecimento Pedagógico Geral é a Gestão de Sala de Aula que apareceu diversas vezes, sendo esse com maior número de excertos nos documentos Planos de Aulas-D2 (119 trechos) e Diários-D3 (79 trechos), referente à organização da aula ministrada pelos licenciandos em suas regências, assim como, a observação de aulas de químicas dos professores supervisores, organização da turma, o perfil e características da classe, recursos utilizados, estrutura física, tempo disponível para aula, gestão do conteúdo que transcendem o âmbito da disciplina que o professor ministra. No trecho a seguir, apresentamos um exemplo desta categoria.

[...] Primeiramente, alguns minutos antes foram organizadas as bancadas e o quadro negro. A professora realizou a chamada em sala de aula e depois encaminhou-se os alunos ao laboratório. Eles se organizaram em torno 4 a 5 alunos por bancadas (Portfólio 2017 - D3).

\section{Conhecimento do Tema}

Para esta categoria foram considerados discursos do conhecimento do tema a ser ensinado e as relações que existem entre os fatos e conceitos principais dentro de um tema com outros conceitos e teorias químicas.

Nesta categoria da Base de Conhecimento foram incluídos 187 trechos, com 2 menções alocados no Conhecimento Sintático relacionado ao conjunto de formas para justificar a validade ou a invalidade de qualquer afirmação sobre determinado fenômeno de conhecimento. Em relação ao Conhecimento Substantivo com 9 trechos categorizados referente a variedade de maneiras em que os fatos e princípios da área são organizados para incorporar os seus conceitos. A respeito do Conhecimento do Conteúdo, subcategoria com 176 trechos, sendo esse com maior número de trechos enquadrados nos documentos, aparecendo com maior ênfase nos planos de aulas (D2) onde estão detalhados os conteúdos 


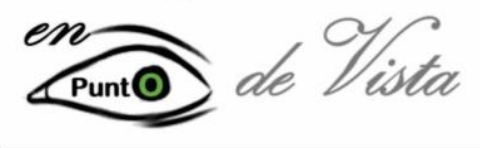

DOI: https://doi.org/10.30705/eqpv.v5i1.2538

desenvolvidos pelos licenciandos. Algumas dessas ações podem ser identificadas nos seguintes discursos:

[...] compreender a organização da tabela periódica e aprender como identificar a localização de um elemento químico por meio da distribuição eletrônica. [...] será explicado a organização dos elementos na tabela periódica enfatizando a ordem crescente dos números atômicos. As definições de elementos translúcidos, naturais e artificiais serão comentadas. Posteriormente será explanado que as linhas horizontais recebem o nome de períodos e as verticais de grupos ou família. Os nomes de cada uma das famílias serão também apresentados e discutidos neste momento. Finalmente será discutido o motivo de o hélio ser mostrado no bloco $p$ e o hidrogênio ser encontrado na maioria das vezes no grupo 1 (Portfólio 2018-D2).

\section{Conhecimento do Contexto}

Em relação a esta categoria foram considerados trechos em que os licenciandos descrevem informações que caracterizam o ambiente escolar, culturais e psicológicas, os conhecimentos dos estudantes, seus interesses pessoais, escolares e profissionais, pontos fortes e imitações dos seus alunos e demais fatores que afetam sua prática de ensino:

[...] O reconhecimento é uma etapa inicial que nos ajuda a entender a realidade da escola, desde o seu funcionamento administrativo/ pedagógico, como também verificar os perfis dos alunos (Portfólio 2017 D4, grifo nosso).

[..] Em relação ao reconhecimento do espaço físico, este me ajudará a analisar quais materiais de suporte estão à minha disposição para auxiliar no desenvolvimento e explicações de determinados conteúdos (Portfólio 2017 -D9, grifo nosso).

Com 161 trechos categorizados neste conhecimento, a subcategoria com maior número de menções são Escola (84 trechos), seguido de Estudante (54 trechos), Comunidade (17 trechos) e Distrito (6 trechos). Em relação aos documentos que mais contém menções às categorias de conhecimento foram as sínteses reflexivas sobre o reconhecimento da escolaD4 e Diário de reconhecimento da escola-D9. Essas atividades são desenvolvidas no reconhecimento escolar, momento em que os licenciandos fazem coleta de informações através de observações, questionamentos orais e escritos, análise de registro e proposta pedagógica da escola e por fim, fazem uma síntese a partir das ações realizadas no diagnóstico escolar.

Numa comparação entre os conhecimentos base da docência evidenciados nos diferentes documentos analisados ao longo dos anos de 2017 e 2018 alguns elementos 

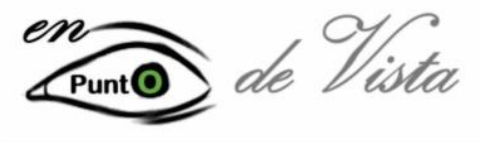

Chemical Education in Point of View

https://revistas.unila.edu.br/eqpv

DOI: https://doi.org/10.30705/eqpv.v5i1.2538

interessantes podem ser percebidos. Comparando a mobilização de conhecimentos da docência no período de 2017 o Conhecimento Pedagógico Geral e Conhecimento do Contexto foram maiores, enquanto no ano de 2018 foram o Conhecimento do Tema e Conhecimento Pedagógico do Conteúdo.

Referente ao Conhecimento Pedagógico Geral (160 em 2017 e 148 em 2018) e ao Conhecimento do Contexto (132 em 2017 e 29 em 2018), esse fato aponta que, por estarem adentrando no espaço escolar, estão mais preocupados em aprender como agir em suas futuras ações de ensino. Os licenciandos fazem uma sondagem sobre o contexto em que estão inseridos, características sociais, organização, funcionamento, o modo de como o professor ensina seus alunos, caraterísticas e perfil dos mesmos, elementos com especial referência no Conhecimento Pedagógico Geral e no Conhecimento do Contexto.

Quanto ao Conhecimento do Tema (91 em 2017 e 96 em 2018) e o Conhecimento Pedagógico do Conteúdo (471 em 2017 e 570 em 2018) serem mais mobilizados no Estágio Curricular Supervisionado do ano de 2018, entendemos que os licenciandos ao estarem mais propícios a pensar o que e como ensinar, que é caracterizado pelo desenvolvimento do projeto de pesquisa sobre a própria prática, destacam principalmente as concepções e propósitos de ensino, posto que, os licenciandos devem tomar decisões sobre as escolhas de conteúdos específicos, procedimento de ensino, estratégias de aprendizagem, utilização de diferentes recursos didáticos e avaliação da aprendizagem.

\section{CONSIDERAÇÕES FINAIS}

O presente trabalho buscou compreender como as diferentes atividades formativas do Estágio Curricular Supervisionado têm contribuído para mobilizar os conhecimentos basilares dos professores de Química em formação inicial. Como resultado, podemos identificar a predominância do Conhecimento Pedagógico do Conteúdo, fundamentado nas estratégias instrucionais para o ensino em determinado conteúdo ministrado pelos licenciandos que contabilizou maior número de menções categorizadas, destacando-se principalmente durante a regência do segundo ano do estágio (realizado em 2018).

A partir das análises dos documentos CoRes e planos de aula observa-se informações mais detalhadas nas ações pedagógicas, propiciando o reconhecimento de estratégias de valor para superar as dificuldades encontradas pelos alunos em determinados conteúdos específicos na disciplina de química.

O Conhecimento do Tema e o Conhecimento Pedagógico Geral, por sua vez, predominaram principalmente na fase de planejamento das atividades, destacando-se principalmente nos documentos de planos de aula, em que predominaram os domínios relacionados ao conhecimento do conteúdo específico de química e a condução das atividades 


\section{Educação Química}
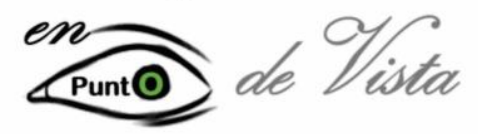

Chemical Education in Point of View

https://revistas.unila.edu.br/eqpv

DOI: https://doi.org/10.30705/eqpv.v5i1.2538

em sala de aula. Porém, na decisão sobre o que ensinar, os licenciandos não baseiam seus conhecimentos sobre o contexto específico dos alunos, ou seja, os professores em formação inicial revelam conhecimento sobre o quê e por que ensinar determinado conteúdo de química, em termos curriculares e de conteúdo, mas não articulam isso ao contexto dos quais os estudantes estão inseridos.

\section{REFERÊNCIAS}

ABELL, S. Research on Science Teacher Knowledge. Handbook of Research on Science Education. p. 1105-1149, 2007.

ALARCÃO, I. (org.). Formação reflexiva de professores: estratégias de supervisão. Porto: Porto Editora, 1996.

ALMEIDA, M. I.; PIMENTA, S. G. (orgs.). Estágios supervisionados na formação docente: educação básica e educação de jovens e adultos. São Paulo: Cortez, 2014.

CARLSEN, Wi. Domains of Teacher Knowledge. In: GESS-NEWSOME, J.; LEDERMAN, N. G. (Eds.) Examining pedagogical content knowledge: the construct and its implications for science teaching. Dordrecht, The Netherlands: Kluwer Academic Publishers, 1999. p. 21-50.

FERNANDEZ, C. Revisando a Base de Conhecimentos e o Conhecimento Pedagógico do conteúdo (PCK) de professores de Ciências. Revista Ensaio. Belo Horizonte. Edição 2015, v. 17, n.500-528. Disponível em: <http://www.scielo.br/pdf/epec/v17n2/1983-2117-epec-17-02-00500.pdf>. Acesso em: 05 jul. 2020.

GROSSMAN, P. L. The making of a teacher: Teacher knowledge and teacher education. New York: Teachers College Press, 1990.

MAGNUSSON, S.; KRAJICK, J.; BORKO, H. Nature, sources, and development of pedagogical content knowledge for science teaching. In: GESS-NEWSOME, J. LEDERMAN, N. G. (Eds.), Examining pedagogical content knowledge: p. 95-132. Dordrecht: Kluwer Academic Publishers, 1999.

MORAES, R.; GALIAZZI, M. C. Análise Textual Discursiva. Ijuí: UNIJUÍ, 2011.

PARK, S.; OLIVER, S. Revisiting the conceptualization of pedagogical content knowledge (PCK): PCK as a conceptual tool to understand teachers as professionals. Research in Science Education, New York, v. 38 , p. $261-284,2008$

ROLLNICK, M.; BENNETT, J.; RHEMTULA, M.; DHARSEY, N., NDLOVU, T. The place of subject matter knowledge in pedagogical content knowledge: a case study of South African teachers teaching the amount of substance and chemical equilibrium. International Journal of Science Education, v. 30, n. 10, p.1365-1387, 2008

SILVA, R. M. G.; SCHNETZLER, R. P. Concepções e ações de formadores de professores de Química sobre o estágio supervisionado: propostas brasileiras e portuguesas. Química Nova[online]. São Paulo, v. 31, n. 8, p. 2174-2183, 2008.

Rede Latino-Americana de Pesquisa em Educação Química - ReLAPEQ 


\section{Educação Química}
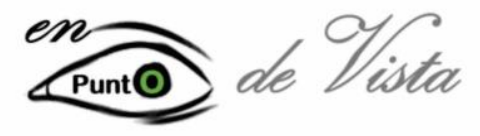

Chemical Education in Point of View

https://revistas.unila.edu.br/eqpv

DOI: https://doi.org/10.30705/eqpv.v5i1.2538

VAN DRIEL, J. H.; VERLOOP, N.; DE VOS, W. . Developing science teachers' pedagogical content knowledge. Journal of Research in Science Teaching, Hoboken, NJ, v. 35, n. 6, p. 673-695, 1998.

SHULMAN, L. S. Knowledge and teaching: Foundations of the new reform. Harvard Educational Review, v. 57, n. 1, p. 1-22, 1987.

SHULMAN, L. S. Those Who understand: Knowledge growth it teaching. Educacional Researcher, v.15, n.2, p.4-14, 1986.

\section{RESUMO}

Este estudo situa-se no campo de formação de professores e objetiva identificar os conhecimentos basilares mobilizados por licenciandos em Química nos diferentes instrumentos de planejamento e ação produzidos na disciplina do Estágio Curricular Supervisionado. As categorias utilizadas na análise foram definidas a priori a partir do modelo proposto por Abell (2007), a saber: Conhecimento do Conteúdo, Conhecimento Pedagógico, Conhecimento Pedagógico do Conteúdo e Conhecimento do Contexto. Como principais resultados temos a predominância do Conhecimento Pedagógico do Conteúdo, fundamentado nas estratégias instrucionais para o ensino. Assim, ressaltamos a importância da variedade de atividades desenvolvidas no Estágio Curricular Supervisionado, que perpassem por diferentes conhecimentos da docência.

\section{RESUMEN}

Este estudio se ubica en el campo de la formación docente y tiene como objetivo identificar los conocimientos básicos movilizados por los estudiantes de Licenciatura en Química en los diferentes instrumentos de planificación y acción producidos en su momento en la asignatura de Práctica Pedagógica Supervisada. Las categorías utilizadas en el análisis se definieron a priori a partir del modelo propuesto por Abell (2007), a saber: Conocimiento del contenido, Conocimiento didático, Conocimiento didático del contenido y Conocimiento del contexto. Como principales resultados tenemos el predominio del Conocimiento Didático del Contenido, basado en estrategias instruccionales para la docencia. Así, destacamos la importancia de la variedad de actividades que se desarrollan en las Prácticas PedagógicasSupervisadas, que permean diferentes conocimientos docentes. 